Review began 10/14/2021 Review ended 10/28/2021 Published 11/02/2021

(c) Copyright 2021

Ambur et al. This is an open access article distributed under the terms of the Creative Commons Attribution License CC-BY 4.0. which permits unrestricted use, distribution, and reproduction in any medium, provided the original author and source are credited.

\section{Recurrent Erythema Multiforme Induced by the Combination of Pembrolizumab and Radiation}

\author{
Austin B. Ambur ${ }^{1}$, Jason Mammino ${ }^{1}$, Rajiv Nathoo ${ }^{1}$ \\ 1. Dermatology, Kansas City University-Graduate Medical Education Consortium/Advanced Dermatology and \\ Cosmetic Surgery, Oviedo, USA
}

Corresponding author: Austin B. Ambur, austin.b.ambur@gmail.com

\begin{abstract}
Erythema multiforme is a self-limited condition that is characterized by the rapid onset of symmetric targetoid lesions. This hypersensitivity reaction is commonly triggered by herpes simplex virus and Mycoplasma pneumoniae infections. Pembrolizumab is an anti-programmed cell death protein 1 (PD-1) inhibitor that is associated with drug-induced erythema multiforme. Radiotherapy is a rarely reported trigger of erythema multiforme. We report a case of recurrent pembrolizumab and radiotherapy-induced erythema multiforme in a patient with stage IV non-small cell lung cancer. This study aimed to highlight a unique cause of erythema multiforme and to review the common radiation-induced cutaneous reactions.
\end{abstract}

Categories: Dermatology, Radiation Oncology, Oncology

Keywords: mycoplasma pnemoniae, herpes simplex virus type 1, clinical dermatology, general dermatology, non small cell lung cancer, radiotherapy (rt), erythema multiforme

\section{Introduction}

Erythema multiforme (EM) is a hypersensitivity reaction that is characterized by a rapid onset of symmetric targetoid lesions. The most common causes are herpes simplex virus (HSV) and Mycoplasma pneumoniae infections. Additional triggers include drugs and physical sources [1]. Radiotherapy is one physical source that has rarely been reported to trigger EM [2-4]. Pembrolizumab is an anti-programmed cell death protein 1 (PD-1) inhibitor that results in cutaneous adverse reactions in up to one-third of patients. These cutaneous reactions include a range of dermatologic manifestations including erythema multiforme, bullous pemphigoid, lichenoid dermatitis, spongiotic dermatitis, vitiligo-like lesions, acneiform eruptions, and lupus-like reaction [5]. The disease is typically self-limited, however, relapses may occur. We report a case of recurrent combined pembrolizumab and radiotherapy-induced EM in a patient with stage IV nonsmall cell lung cancer.

\section{Case Presentation}

A 68-year-old black male with a history of stage IV non-small cell lung cancer with metastasis to his spine and kidney status post partial lobectomy three years prior, benign prostate hyperplasia, and hypertension presented with recurrent EM minor. Seven months prior to his presentation, oncology initiated a regimen of cisplatin, pemetrexed, and pembrolizumab. After six cycles of this regimen, treatment was discontinued due to intolerable side effects including vitiliginous and eczematous cutaneous changes. He was therefore treated with five days of stereotactic body radiotherapy (SBRT) to his chest. He received a total dose of 5500 cGy. The patient initially presented to our clinic five weeks post-radiation. He had an expanding eroded vesicular eruption concentrated to the site of irradiation of two weeks duration (Figures 1,2). 


\section{Cureus}

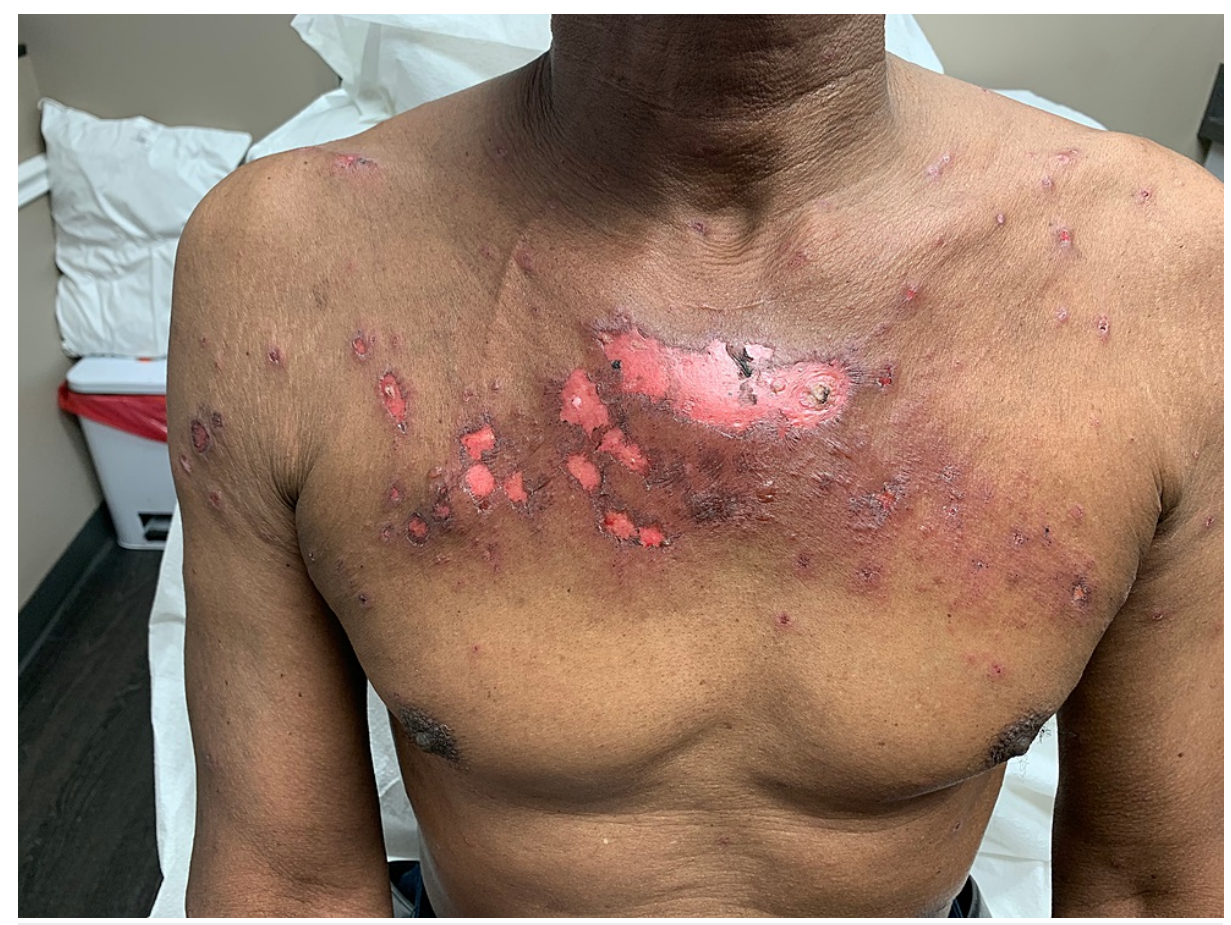

FIGURE 1: Eroded plaques to the mid-chest with surrounding targetoid and vesicular lesions.

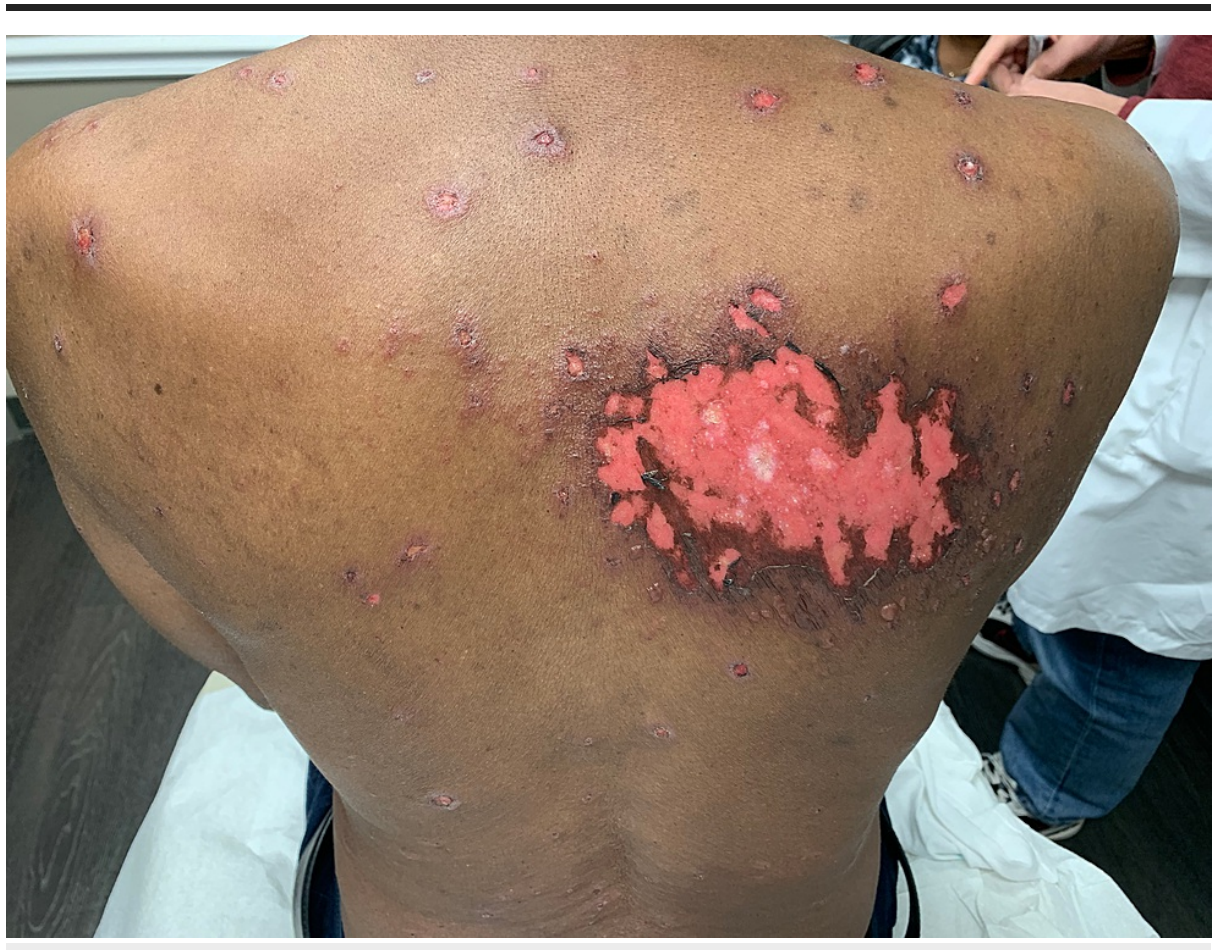

FIGURE 2: Eroded plaques to the upper back with surrounding targetoid and vesicular lesions.

Hematoxylin-eosin (H\&E) staining via punch biopsy performed on a lesional vesicle to the upper back showed scattered necrotic keratinocytes within the epidermis with necrosis of the epidermis, separation of the dermo-epidermal junction, and an underlying interface and superficial perivascular inflammatory cell infiltrate of lymphocytes and rare eosinophils consistent with EM (Figures 3, 4). 


\section{Cureus}

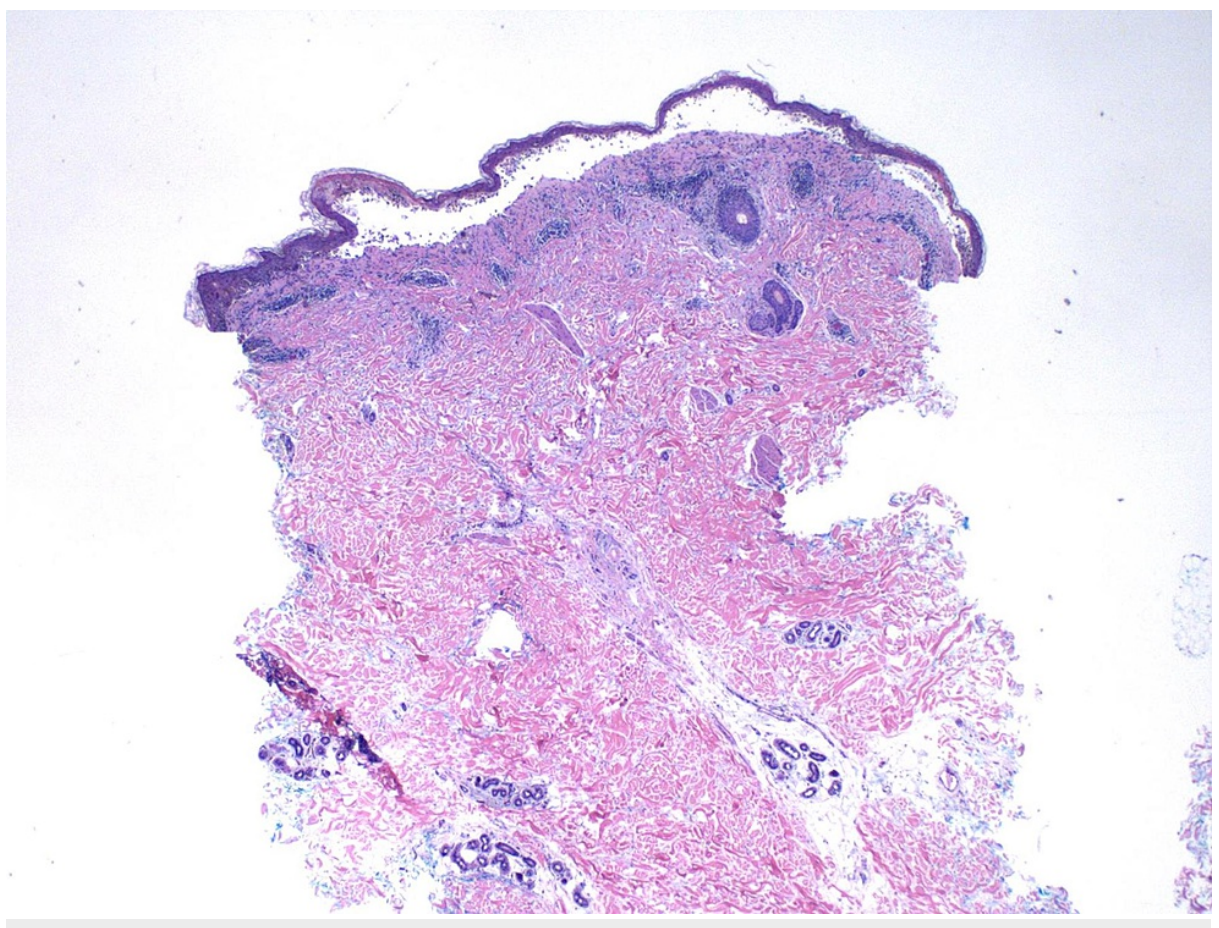

FIGURE 3: Hematoxylin and eosin-stained tissue section of skin from upper back (original magnification $\mathbf{x 2}$ ).

The section of skin shows showing scattered necrotic keratinocytes within the epidermis with necrosis of the epidermis, separation of the dermo-epidermal junction, and an underlying interface and superficial perivascular inflammatory cell infiltrate of lymphocytes and rare eosinophils.

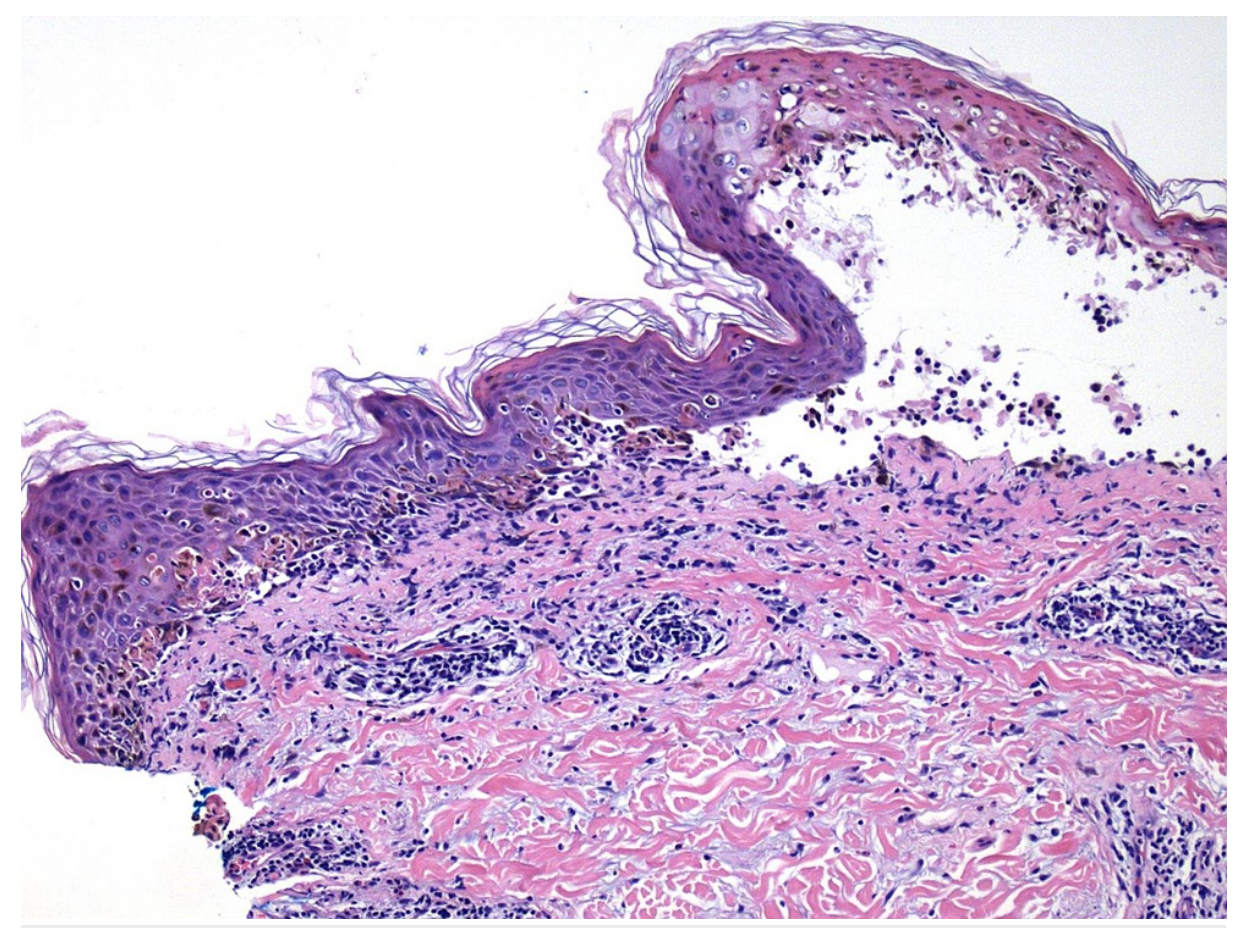

FIGURE 4: Hematoxylin and eosin-stained tissue section of skin from upper back (original magnification $\mathbf{x} 10$ ).

The section of skin shows scattered necrotic keratinocytes within the epidermis with necrosis of the epidermis, separation of the dermo-epidermal junction, and an underlying interface and superficial perivascular inflammatory cell infiltrate of lymphocytes and rare eosinophils. 


\section{Cureus}

Direct immunofluorescence (DIF) was negative for other vesiculobullous diseases and bacterial culture was negative. Viral studies for herpes-simplex-virus (HSV) and Mycoplasma pneumoniae were remarkable for elevations in IgG without IgM. Daily medications included alfuzosin but were otherwise unremarkable for any new triggers. Pembrolizumab-induced EM has been reported to occur between three to 35 months after starting treatment and was postulated to be the initiating trigger of EM [5]. Radiotherapy was also implicated in the development of EM as the skin lesions started in the irradiated area. Our patient was treated with topical $0.1 \%$ triamcinolone ointment BID and showed significant improvement (Figures 5, 6).

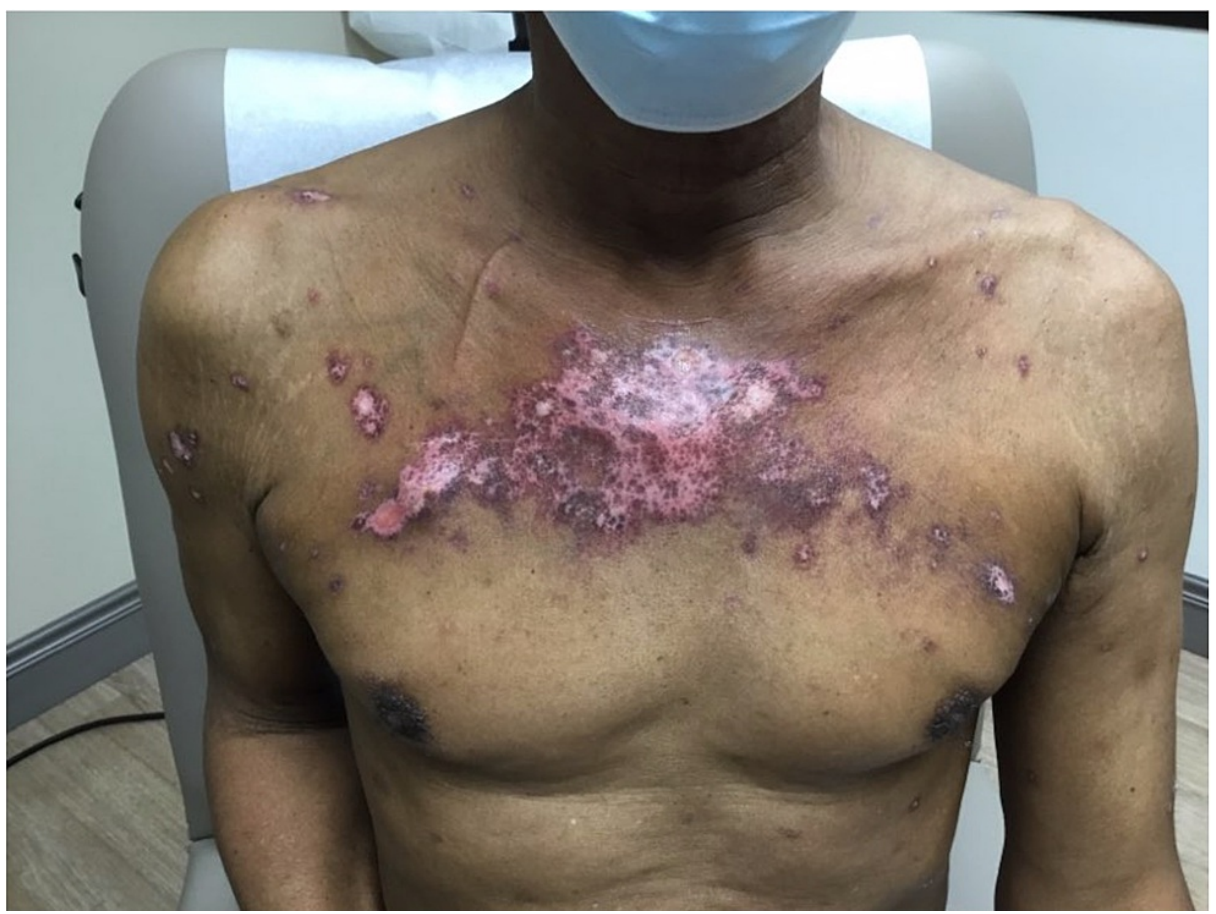

FIGURE 5: Healing central wounds with surrounding areas of postinflammatory pigmentary changes located on the mid-chest. 


\section{Cureus}

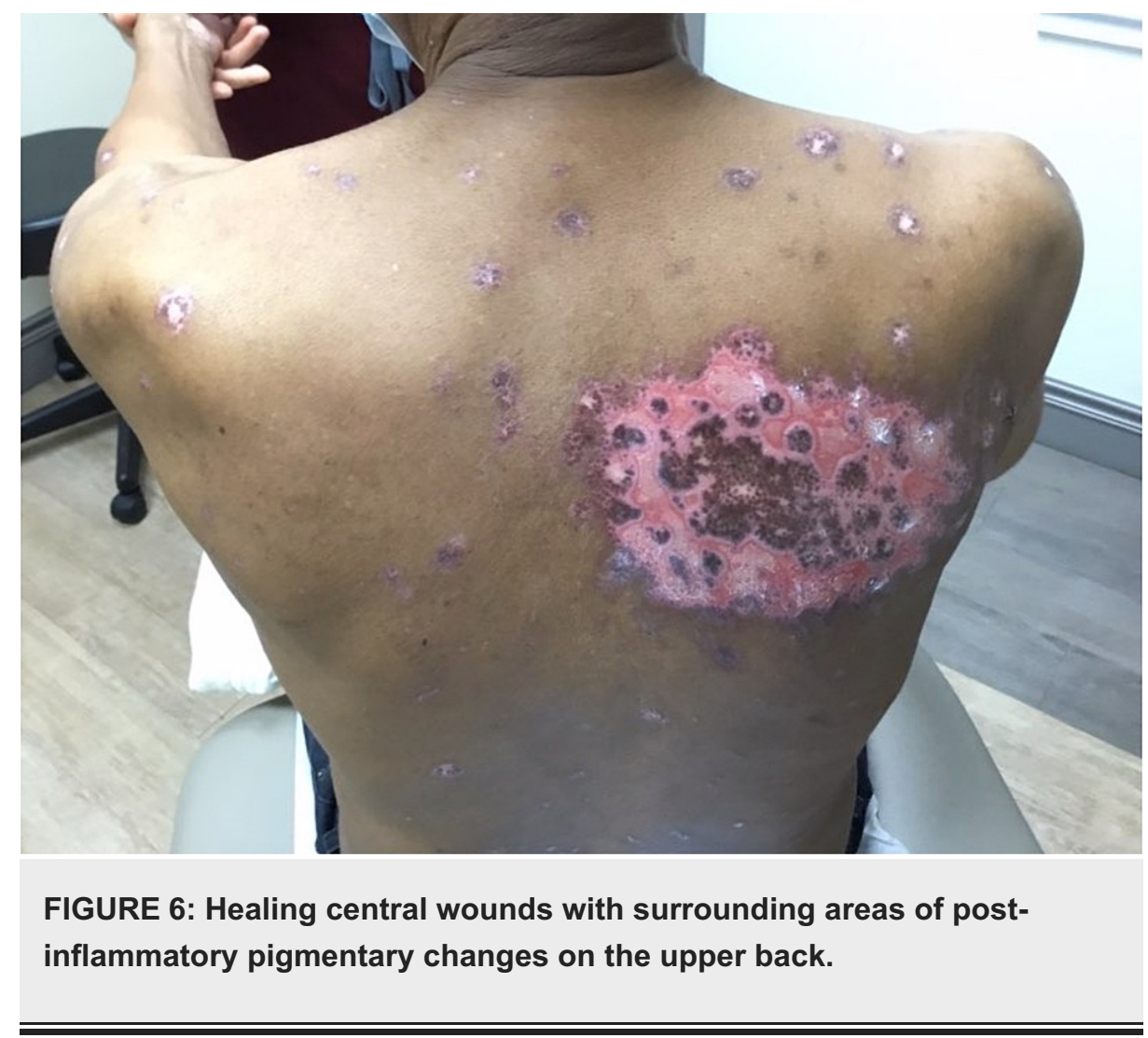

At five weeks after the initial visit, the patient presented with multiple subtle erythematous papules at sites distant from the main truncal lesions. Despite increasing the potency of his topical steroid to betamethasone dipropionate, the lesions evolved quickly into papular targetoid lesions covering much of the upper body, sparing the head (Figure 7). 


\section{Cureus}

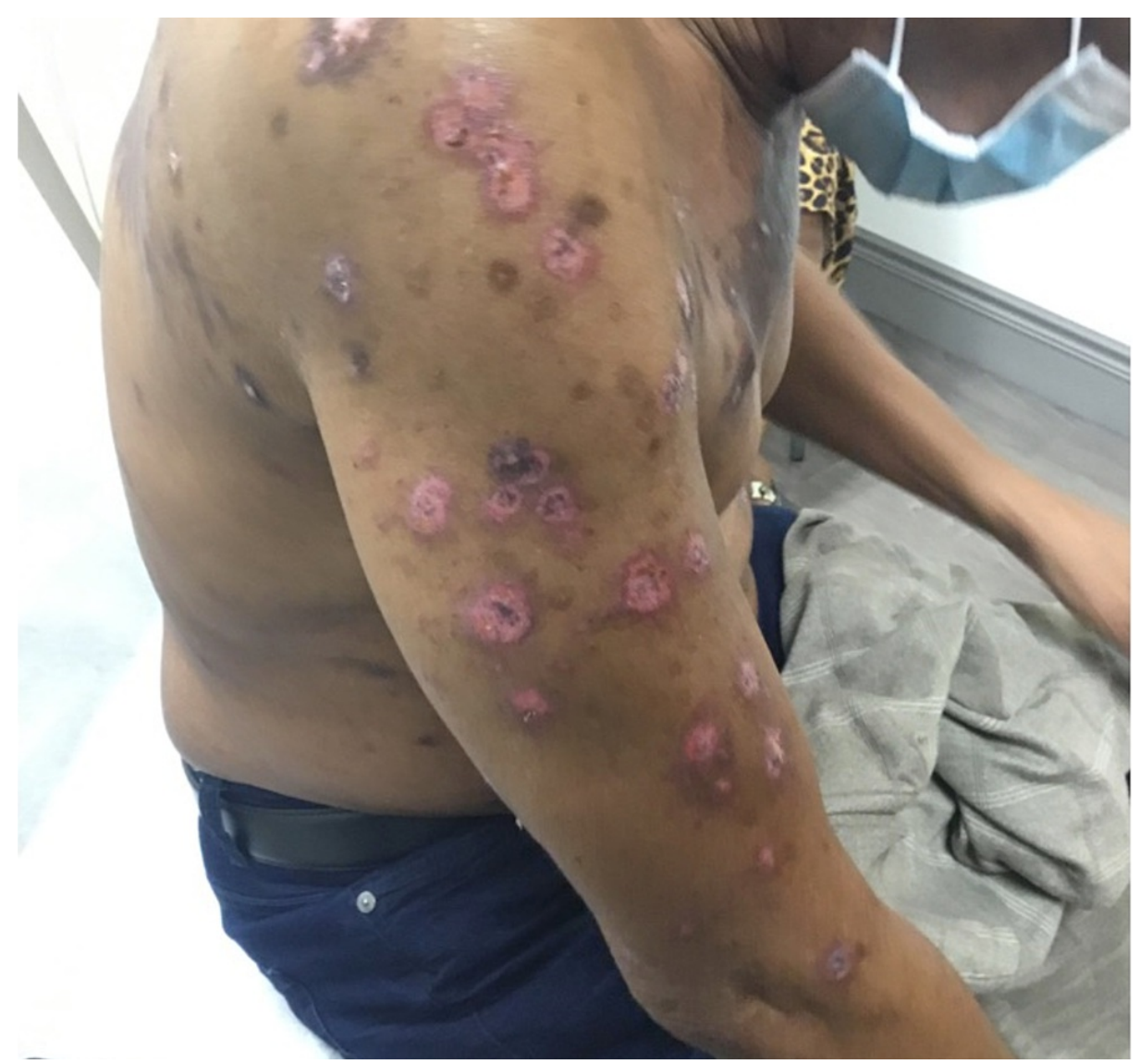

FIGURE 7: Numerous eroded papular targetoid lesions on the right arm.

Given the recurrent nature of the lesions, he was started on daily valacyclovir $500 \mathrm{mg}$ twice daily. Our patient continued to develop recurrent lesions despite suppressive antiviral therapy and therefore was ultimately started on dapsone.

\section{Discussion}

EM is characterized by the rapid onset of numerous symmetric fixed red papules that evolve into targetoid lesions. EM is subdivided into EM minor and EM major. They are distinguished by the absence of mucosal involvement and systemic symptoms in EM minor. The disease is self-limited and typically resolves within two weeks for EM minor and six weeks for EM major [1]. It is important to note that EM is characterized by papules as it may be mistaken for Stevens-Johnson syndrome or toxic epidermal necrolysis, which are characterized by macular lesions with a higher likelihood of mucosal involvement. The most common cause of EM minor is HSV-1 whereas EM major is more commonly associated with Mycoplasma pneumoniae infection [1]. Several drugs have been described in the literature in association with EM, including nonsteroidal anti-inflammatory drugs (NSAIDs), sulfonamides, anticonvulsants, and allopurinol [1]. Pembrolizumab is a PD- 1 inhibitor that is a less commonly reported trigger of EM [5]. The PD-1 receptor is expressed on the active cluster of differentiation $4\left(\mathrm{CD}^{+}\right) \mathrm{T}$ cells and plays an important role in downregulating $\mathrm{T}$ cell proliferation, reducing cytotoxic activity, and the expansion of regulatory T cells [6]. PD-1 inhibition may also enhance the expression of Fas receptors on keratinocytes [7]. Interaction of Fas ligand on $\mathrm{T}$ cells with Fas receptors on keratinocytes leads to apoptosis of keratinocytes and may be involved in the pathogenesis of pembrolizumab-induced EM. Physical sources that may induce EM include trauma, cold, and UV and X-ray irradiations [1]. The cause of radiotherapy-induced EM is unknown. It has been postulated that radiotherapy may induce an immune-based hypersensitivity reaction by the toxic breakdown products during treatment [3]. Radiotherapy may also lead to a hypersensitivity reaction by preferentially impairing Tsuppressor cells. The hypersensitivity reaction induced by radiotherapy may have had synergistic and/or complementary contributions to the immune dysregulation induced by pembrolizumab and the development of EM. Several conditions known to be associated with radiation include radiodermatitis, recall phenomenon, Stevens-Johnson syndrome, and toxic epidermal necrolysis [8]. It is important to recognize the etiology, unique phenotypical findings, and timing of the cutaneous reaction associated with various radiation-induced cutaneous reactions (Table 1). 


\section{Cureus}

\begin{tabular}{|l|l|l|l|}
\hline Inflammatory Condition & Latency Period & Affected Region & Clinical Morphology \\
\hline Erythema multiforme & $10-20$ days & $\begin{array}{l}\text { Irradiated field }+ \\
\text { dissemination }\end{array}$ & Maculopapular \\
\hline Radiodermatitis & 2 weeks & Irradiated field & Erythema/desquamation/ulceration \\
\hline $\begin{array}{l}\text { Recall phenomenon } \\
\text { Stevens-Johnson syndrome/toxic epidermal } \\
\text { necrolysis }\end{array}$ & $\begin{array}{l}1 \text { week to } \\
\text { months }\end{array}$ & Irradiated field & Eryamation/edema \\
\hline
\end{tabular}

TABLE 1: Radiation-induced cutaneous reactions

Initial treatment includes topical steroids in mild cases and systemic steroids in severe diseases. Chronic suppressive antiviral therapy can be implemented for recurrent disease. Azathioprine, thalidomide, dapsone, cyclosporine, mycophenolate mofetil, and psoralen and ultraviolet light A (PUVA) may be used if the condition is resistant to antiviral therapy [1].

\section{Conclusions}

We present a case of recurrent combined pembrolizumab and radiotherapy-induced EM minor to highlight a unique cause of EM that has been rarely described. We hypothesize that pembrolizumab was the initiating trigger for EM and was exacerbated by radiotherapy. We also use this case to demonstrate the possible recalcitrant nature of the disease. It is important to understand the various radiation-induced cutaneous reactions and their distinct clinical features to make the correct diagnosis and reduce the delay in appropriate therapy.

\section{Additional Information}

\section{Disclosures}

Human subjects: Consent was obtained or waived by all participants in this study. Conflicts of interest: In compliance with the ICMJE uniform disclosure form, all authors declare the following: Payment/services info: All authors have declared that no financial support was received from any organization for the submitted work. Financial relationships: All authors have declared that they have no financial relationships at present or within the previous three years with any organizations that might have an interest in the submitted work. Other relationships: All authors have declared that there are no other relationships or activities that could appear to have influenced the submitted work.

\section{References}

1. Bolognia JL, Schaffer JV, Cerroni L: Erythema multiforme, Stevens-Johnson syndrome and toxic epidermal necrolysis. Dermatology. Fourth Edition. Elsevier, China; 2018.

2. Salomon D, Saurat JH: Erythema multiforme associated with radiotherapy . Dermatologica. 1989, 179:110-1. $10.1159 / 000248332$

3. Veness MJ, Dwyer PK: Erythema multiforme-like reaction associated with radiotherapy. Australas Radiol. 1996, 40:334-7. 10.1111/j.1440-1673.1996.tb00414.x

4. Pandya AG, Kettler AH, Bruce S: Radiation-induced erythema multiforme. An unusual presentation with elastic tissue phagocytosis. Int J Dermatol. 1989, 28:600-2. 10.1111/j.1365-4362.1989.tb02537.x

5. Wang LL, Patel G, Chiesa-Fuxench ZC, et al.: Timing of onset of adverse cutaneous reactions associated with programmed cell death protein 1 inhibitor therapy. JAMA Dermatol. 2018, 154:1057-61. 10.1001/jamadermatol.2018.1912

6. Toor SM, Syed Khaja AS, Alkurd I, Elkord E: In-vitro effect of pembrolizumab on different T regulatory cell subsets. Clin Exp Immunol. 2018, 191:189-97. 10.1111/cei.13060

7. Utsunomiya A, Oyama N, Iino S, Baba N, Chino T, Utsunomiya N, Hasegawa M: A case of erythema multiforme major developed after sequential use of two immune checkpoint inhibitors, nivolumab and ipilimumab, for advanced melanoma: possible implication of synergistic and/or complementary immunomodulatory effects. Case Rep Dermatol. 2018, 10:1-6. 10.1159/000485910

8. Hernández Aragüés I, Pulido Pérez A, Suárez Fernández R: Inflammatory skin conditions associated with radiotherapy. Actas Dermosifiliogr. 2017, 108:209-20. 10.1016/j.ad.2016.09.011 